\title{
REABILITAÇÃO PSICOLÓGICA DE PACIENTES COM SEQÜELAS DA ENCEFALITE POR ARBOVIRUS
}

Anency Giannotti Hallage *

\begin{abstract}
GIANNOTTI - HALLAGE, A. Reabilitação psicologica de pacientes com sequielas da encefalite por arbovirus. Rev. Saúde públ., S. Paulo, 15:478-84, 1981.

RESUMO: Foi investigado o possivel comprometimento psiquico de pacientes com sequelas da encefalite por arbovirus, do litoral sul do Estado de Săo Paulo (Brasil), com a finalidade de definir o papel do psicólogo, em um programa de reabilitação física e psicossocial. A presença das sequielas era encarada de forma depreciativa e observou-se que essa percepçäo comprometeu fundamentalmente a identidade do paciente como ser humano, trazendo uma série de respostas emocionais desadaptadas e impossibibilitando a convivência satisfatória consigo e com o próximo. Os resultados analisados, em seu aspecto psicussociologico, revelaram que as dificuldades psiquicas observadas eram originárias da maneira como a deficiência física é encarada no meio social.
\end{abstract}

UNITERMOS: Reabilitação. Psicologia. Encefalite por arbovirus. Psicoterapia.

\section{INTRODUÇAO}

O presente trabalho procurou definir a atuação do psicólogo dentro de um programa de equipe multidisciplinar (médico, psicólogo, assistente social e sanitarista) de Reabilitação Física e Psicossocial de pacientes, do litoral sul do Estado de São Paulo, com sequielas da encefalite por arbovirus, promovido pela Coordenadoria de Assistência Hospitalar, da Secretaria da Saúde do Estado de São Paulo.

A relevância deste trabalho se dá pela escassa literatura encontrada, sobre reabilitação psicológica de pacientes com seqüelas da encefalite. E surgiu como uma necessidade, após o surto dessa enfermidade ocorrido no Estado de São Paulo, e que teve sua ascensão máxima em $1976^{3,5}$. Além disso, embora se aponte a importância de promover 0 bem estar psíquico do paciente, como um dos itens constantes de programas de reabilitação no sentido amplo, em geral há predominância do enfoque da recuperação fisica. O psicólogo é indicado para atender as exigências psicométricas ou de avaliação de casos específicos. O papel do psicólogo na avaliação do comprometimento psíquico do paciente, em presença de enfermidades orgânicas, não é comumente valorizado pela equipe multidisciplinar.

A presença da doença física, em geral, constitui-se em fonte de tensão emocional e tende a perturbar o equilíbrio psíquico do paciente ${ }^{1}$. Esse desequilibrio se agrava, nos casos em que não há uma remissão total da enfermidade. $O$ comprometimento psicológico do paciente depende, não somente da

" Do Instituto "Dante Pazzanese" de Cardiologia da Secretaria de Estado da Saúde de São Paulo. Av. Dante Pazzanese, 500 - 04012 - São Paulo.SP - Brasil. 
GIANNOTTI-HALLAGE, A. Reabilitação psicológica de pacientes com sequielas da encefalite por arborivus. Rev. Saúde pübl., S. Paulo, 15:478-84, 1981.

enfermidade em si mas, principalmente, da maneira como ele encara a sua realidade física e do valor afetivo atribuído a ela, trazendo consigo uma série de respostas emocionais desadaptadas.

A maneira como a enfermidade é percebida, por sua vez, é o resultado, tanto das características intrínsecas da personalidade do enfermo, como também, das características do meio social em que ele vive $e_{\text {, }}$ en particular, da maneira como a enfermidade é percebida nesse meio ${ }^{1,2,4,6}$.

O planejamento para a reabilitação psicológica do paciente, com sequielas da encefalite, deverá procurar determinar de que modo o paciente encara e se comporta, em presença da moléstia e da seqüela, bem como a possibilidade de um comprometimento psíquico em função dessa percepção.

\section{MATERIAL E MÉTODO}

Em agosto de 1976 foram seleciunados 6 pacientes (Tabela 1), e 3 de seus familiares, incluídos num levantamento realizado por sanitaristas, dos pacientes com seqüelas de encefalite por arbovirus, residentes no Vale do Ribeira, Estado de São Paulo). Eram 4 do sexo masculino e 2 feminino, com idades entre 17 a 53 anos, sendo 2 jovens estudantes, 2 trabalhadores braçais, 1 operário e 1 do lar. Três deles eram brancos, 2 pardos e 1 negro.

Todos os pacientes apresentavam vários tipos de impedimento físico: paralisia, parestesia ou incoordenação motora de membros superiores ou inferiores, paralisia facial, disartria, e perda parcial da capacidade auditiva ou da visão (Tabela 1).

Utilizou-se como método de investigação a entrevista psicológica individual e em grupo. Foram realizadas duas entrevistas individuais e duas grupais. Estas duas últimas foram constituídas pela reuniảo de todos os pacientes, contando com a participação de um familiar e pela reunião de 1 paciente e 3 de seus familiares.

Informava-se aos entrevistados que se pretendia verificar suas principais difi- culdades, no que tangia ao fato de haverem contraído a enfermidade. Deu-se preferência a que os entrevistados discorressem livremente sobre elas, evitando-se ao máximo a indução de respostas por parte do entrevistador.

\section{RESULTADOS}

Os pacientes enfocaram, nas entrevistas, predominantemente, 0 comprometimento ísico deixado pela enfermidade e suas consequiências, percebidas como desastrosas para a sua vida pessoal. Os familiares complementaram as informações dos pacientes, ao relatarem sobre suas experiências com os mesmos, após a ocorrência da enfermidade. Comentaram sobre as alterações do humor e comportamento que apresentaram e sobre as suas dificuldades, no contacto diário com eles.

É possível distinguir, no grupo de pacientes estudados, diferentes graus de comprometimento funcional. Conseqüentemente ao grau de déficit funcional, motriz, auditivo, visual, entre outros, os pacientes tornaram-se mais, ou menos desprovidos dos recursos motores e sensoriais, indispensáveis para interpretar e responder aos estímulos ambientais. No primeiro grupo, estariam os de maior comprometimento pela perda total de determinadas funções. No segundo grupo, estariam os de comprometimento menos acentuado pela perda parcial delas. A combinação de dois ou mais comprometimentos leves, entretanto, resultam num comprometimento mais amplo, em função do déficit generalizado.

Observou-se, porém, que a avaliação que os pacientes faziam de si independia, muitas vezes, do grau de deficiência funcional que possuiam. Constituiram-se elementos muito importantes dessa avaliação, o grau em que as sequielas eram percebidas como mais, ou menos facilmente reconheciveis, e o quanto os pacientes podiam dominar o seu meio ambiente sozinhos, ou depender do próxımo para realizar o que desejassem. Observou- 
GIANNOTTI-HALLAGE, A. Reabilitação psicológica de pacientes com sequelas da encefalite por arborivus. Rev. Saúde públ., S. Paulo, 15:478-84, 1981.

T A B E L A 1

Seqüelas da Encefalite por Arbovirus - Quadro de distribuição dos pacientes estudados, segundo dados pessoais e os diversos tipos de sequielas da Encefalite por Arbovirus.

\begin{tabular}{|c|c|c|c|c|c|}
\hline Sexo & $\begin{array}{l}\text { Idade em anos } \\
\text { completos }\end{array}$ & Raça & Estado civil & Ocupaçăo & Seqtielas \\
\hline feminino & 17 & parda & solteira & estudante & $\begin{array}{l}\text { - incoordenação motora dos } \\
\text { membros s"periores }\end{array}$ \\
\hline feminino & 45 & branca & casada & do lar & $\begin{array}{l}\text { - paralisia dos membros } \\
\text { inferiores; paralisia fa- } \\
\text { cial direita; perda par- } \\
\text { cial da capacidade audi- } \\
\text { tiva e visual. }\end{array}$ \\
\hline masculino & 19 & branca & solteiro & estl:dante & $\begin{array}{l}\text { - parestesia do membro } \\
\text { inferior esquerdo. }\end{array}$ \\
\hline masculino & 35 & parda & solteiro & pedreiro & $\begin{array}{l}\text { - incoordenação motora dos } \\
\text { membros inferiores; per- } \\
\text { da parcial da capacidade } \\
\text { visual. }\end{array}$ \\
\hline masculino & 35 & branca & solteiro & operário & $\begin{array}{l}\text { - paralisia do membro su- } \\
\text { perior esquerdo; inco- } \\
\text { ordenação motora dos } \\
\text { membros inferiores. }\end{array}$ \\
\hline masculino & 58 & negra & casado & braçal & $\begin{array}{l}\text { - paralisia dos membros } \\
\text { inferiores; incoordenação } \\
\text { motora do membro su- } \\
\text { perior direito; disartria; } \\
\text { perda parcial da capa- } \\
\text { cidade visual. }\end{array}$ \\
\hline
\end{tabular}

-se; ainda, que a percepção de maior ou menor grau de deficiência funcional dependia da situação que o paciente estava exposto e do estímulo que iria responder. Implicava que ele percebesse a sequiela como um obstáculo que se antepunha à satisfação de alguma necessidade particular. Como exemplo, a impossibilidade de coordenar os movimentos articulares da escrita.

Demonstraram que, embora portadores de seqüelas diversas quanto ao grau e natureza das funções envolvidas, encontravam-se numa situação semelhante, por responder a elas de forma semelhante ou segundo o mesmo sistema de referência. As sequielas configuravam um estado de invalidez $p$ multilação física e atribuiam a elas uma conotação depreciativa.

As dificuldades mais mencionadas pelos entrevistados podem ser relacionadas de acordo com os seguintes tópicos:

\section{Perda de autonomia de ação}

Quanto mais impossibilitados de se moverem livremente e realizarem o que desejassem, mais tornaram-se excluídos de muitas atividades da vida cotidiana e mais neces. sitavam do próximo para complementar suas deficiências funcionais. Alguns necessitavam do auxilio das pessoas para se locomover e até mesmo para a satisfação das mais simples necessidades corporais básicas. 
GIANNOTTI-HALLAGE, A. Reabilitação psicológica de pacientes com sequelas da encefalite por arborivus, Rev. Saüde pübl., S. Paulo, 15:478-84, 1981.

A dependencia física do próximo implicava também numa dependência moral. $O$ relacionamento com os demais tornou-se desigual e consideravam expostos a uma situação humilhante. De un lado, necessitando do seu auxílio para realizar seus intentos, percebiam-se como uma "carga" para o próximo $\epsilon$ em divida para com eles; de outro, ficavam sujeitos à vontade e autoridade alheias, ou por dependerem da disponibilidade das pessoas para efetivar seus desejos, ou porque, não dispondo dos recursos da defesa física, tornavam-se expostos às imposições depreciativas ou coercitivas do próximo.

Observou-se que havia uma tendência a situar o impedimento físico, além de seus limites reais. Os que lidavam com os pacientes tendiam a estender o comprometimento a funções não atingidas, e a percehê-los como incapacitados para funções que poderiam desempenhar. Os pacientes, por sua vez, evitavam expor-se aos seus limites funcionais, quer pelo temor ao fracasso, o receio à perda de equilíbrio, e a queda, quer pelo sentimento de se sujeitar a tıma situação que os ridicularizava.

\section{Sentimento de perda da identidade}

Todos os pacientes queixaram-se de que a presença das seqüelas da encefalite alteraram, significativamente, a imagen que possuiam de si. Não somente pelas mudanças ocorridas na sua vida pessoal, mas também, e principalmente, pela conotação depreciada dada à sua aparência física.

"Não sou mais o que era antes. Choro quando vejo meus colegas trabalhando" (braçal, 53 anos, Tabela 1).

"Saí da escola porque sentia vergonha das minhas colegas" (estudante, 17 anos, Tabela 1).

Avaliavam o seu corpo, tendo como base a comparação com o próximo ou consigo no período anterior à enfermidade. Ao lado ae um comprometimento funcional, as seciüelas comprometeram a sua identidade como pessoa humana. Percebiam a sua condição física como incompativel com a de um ser humano normal. Despojados de determinadas características físicas, que outros possuiam, abominavam o seu corpo, percebiam-se indígnos, incompletos, inferiores, tendo como resultante o sentimento de vergonha e humilhação.

\section{Alteraçóes do humor $e$ do comportamento}

Os pacientes fizeram referências a epsódios de intensos sentimentos de tristeza, desânimo, angústia e depressão. Mudavam de humor frequientemente, percebiam-se mais vulneráveis e sensiveis, choravam ou impacientavam com facilidade e sentiam haver perdido a confiança em si.

Segundo o testemunho dos familiares $e$ dos próprios pacientes, as relações entre ambos tornaram-se conflitivas. Os primeiros alegavam uma impussibilidade de compreendê-los e auxiliá-los adequadamente, pois eles oscilavam entre a agressividade, a reivindicação e o ressentimento, quer fossem auxiliados, deixados à vontade, quer suas solicitações não fossem prontamente atendidas. Apontaram a timidez, a sensibilidade exagerada e o retraimento social observados neles e desesperavam-se ante suas tristezas, chocavam-se com a sua agressividade. Os pacientes, por sua vez, reclamavam tanto da falta de atenção ou compreensão por parte dos familiares, como também da abnegação desnecessária, quando não podiam realizar qualquer movimento sem que os familiares interviessem. Admitiram terem se tornado déspotas e agressivos, exigindo a satisfação imediata de seus pedidos, e que ficavam ressentidos com - esquecimento ou a demora na execução deles. Apiedavam-se de si mesmos, e apontavam um futuro sem qualquer esperança, uma vez que o destino havia lhes roubado as oportunidades que, por direito, julgavam-se merecedores: o respeito próprio e dos demais e uma participação efetiva como membro da comunidade.

"Vou me internar num colégio de freiras" (estudante, 17 anos, Tabela 1). 
GIANNOTTI-HALLAGE, A. Reabilitação psicológica de pacientes com sequelas da encefalite por arborivus. Rev. Saúde públ., S. Paulo, 15:47ع-84, 1981.

"Não vou sarar nunca mais" (braçal, 53 anos, Tabela 1).

Ao mesmo tempo guardavam uma intima esperança de remissão total das seqüelas, evidenciada através da reivindicação fundamental: o retorno a sua condição física anterior à enfermidade.

\section{Comprometimento das relaçōes sociais}

Os pacientes, em geral, evitavam qualquer tipo de interação com as pessoas, quer fossem conhecidas ou não. A principal fonte da vulnerabilidade aos contactos sociais era originária de uma preocupação com a aparência física e o grau em que percebiam as sequielas como um traço visivel, que poderia se antepor ao relacionamento com os demais. Assim sendo, no grupo, apenas um caso (estudante, 19 anos, parestesia do membro inferior esquerdo, Tabela 1), sentia-se privilegiado e não se considerava excluido da participação social, pelo fato de se perceber portador de um comprometimento físico menos facilmente reconhecivel.

o sentimento de exclusão social, porém. aparentemente independia do grau de comprometimento físico propriamente dito, mas sim do grau em que as sequielas eram percebidas pelo paciente como mais ou menos visiveis, tanto que a estudante de 17 anos, também portadora de um impedimento leve, não encarava da mesma forma (incoordenação motora dos membros superiores, Tabela 1).

Todos os pacientes, entretanto, estavam interiormente envolvidos com o seu impedimento físico e previam uma relação conflitiva com o próximo. Mesmo a recusa, em se considerar excluído do meio social, implicava numa busca de interação baseada numa suposição percebida como falsa a seu respeito:

"Eu pareço normal" (estudante, 19 anos, Tabela 1).

A principal dificuldade aos contactos sociais era o fato de se perceberem despojados de atributos que conferem norma- lidade, que os tornava diferentes, ultrajados $\epsilon$ inferiorizados. Assim, receavam o descrédito e que a sua condição física se impusesse de tal forma que impedisse a atenção a outros atributos da sua pessoa. Receavam a invasão da sua intimidade por perceberem as seqüelas com a capacidade intrínseca de revelar seus sentimentos mais profundos, ou que as reações do próximo atuassem como um espelho de seus próprios sentimentos. Esperavam ser mal recebidos, como não aceitavam a si mesmos.

\section{DISCUSSAO E CONCLUSOES}

A reivindicação fundamental dos pacientes estudados foi o retorno a sua condição física anterior à enfermidade. Nela situa-se a fonte da impaciência, da agressividade, do ressentimento, da falta de confiança em si, da desesperança e da exclusão social. $O$ ponto central de vulnerabilidade e desadaptação emocional do paciente com seqüelas da encefalite constituiu-se a percepção de si como despojados de um valor imaginário: determinados atributos que conferem normalidade. A concepção de seu eu como incompatível com a de um ser humano normal, dificulta a convivência satisfatória consigo i com os outros e, particularmente, dificulta a adaptação à deficiência física.

O trabalho do psicólogo está intimamente relacionado à atuação de outros profissionais que participam de um programa de reabilitação. Ao lado de estímulos físicos, voltados para a recuperação funcional, o paciente deverá receber estímulos psicológicos a fim de recobrar o seu equilíbrio psíquico.

O paciente será auxiliado no sentido de:

- reavaliar a concepção de si mesmo e da visão do outro, de seu passado e de seu futuro e a sua identidade como ser humano, sem falsas suposições no que tange a sua real condição física;

- encontrar um estilo de vida compativel com suas possibilidades, tanto no sentido de não restringir o campo de suas atividades, vencendo o temor a expor-se 
CiANNOTTI-HALLAGE, A. Reabilitação psicológica de pacientes com sequielas da encefalite por arborivus. Rer. Saude públ., S. Paulo, 15:478-84, 1981.

aos seus limites funcionais, como também aceitando responsabilidades, sem falsos direitos ou privilégios e sem o apiedamento passivo de si mesmo;

- evitar o sentimento de exibição e de autoconsciência exagerada, afastando a sequiela como fonte preponderante de interesse e o foco central de seu pensamento;

- evitar o retraimento social, o sentimento de exclusão e a predisposição negativa com relação ao próximo;

- desenvolver suas aptidōes pessoais, encontrar novos interesses e atividades, quer artisticas, intelectuais ou manuais que compensem suas deficiências, conscientizando-se de que a perda de determinadas funções não implica necessariamente impossibilidade de trabalhar.

O sucesso da aplicação de um programa de reabilitação no sentido amplo, depende do montante de esforço que o paciente está disposto a investir nele. $O$ seu grau de motivação, por sua vez, depende da sua vida afetiva, particularmente da maneira como encara o seu impedimento físico e das perspectivas com relação a sua vida pessoal. O paciente estará desencorajado, se esperar aquém ou muito além das possibilidades reais de recuperação. Estará estimulado se a perceber como um desafio a ser superado, através de pequenas aquisições. A reabilitação física e psicológica, em particular, complementam-se entre si. A melhora do estado psicológico facilita a recuperação física. A restauração das funçōes articulares e musculares, por outro lado, ao lhes proporcionar satisfaçōes efetivas, proporcionam também uma melhora do estado psíquico do paciente.

Uma análise da concepção auto-depreciativa, que os pacientes mostraram possuir, parece revelar que a patologia da pessoa estigmatizada é, antes de tudo, social, que situada a nivel individual 2. A maneira como percebe o seu estado e a si é o reflexo da maneira como a sociedade é constituida. Dificuldades dessa natureza decorrem da existência de normas de identidade social, ou seja, de papéis pré-estabelecidos a serem desempenhados por seus membros, e porque a presença de desfigurações físicas sãu percebidas como um atributo que confere um valor depreciativo a aqueles que as possuem. Ao adquirir uma deficiência física, a pessoa incorpora as crenças sociais de identidade em relação ao que significa possui-la. Experimenta uma mudança aparente de seu eu porque passa a alinhar-se dentre de um quadro de referência já estabelecido $\epsilon$ que foi aprendido por ela: a identidade social do anormal como imperfeito e sub-humano. Assim, a presença da deficiência física, para Goffman ${ }^{2}$ (1975), não favoreceria a desintegração do ego, mas a ocorrência de um fenômeno que poderia ser explicado pela psicologia normal: o doloroso sentimento de conhecer-se no seu novo papel, que antes percebia como localizado no próximo. Neste sentido não haveria uma solução possivel para o deficiente físico, porque embora admita-se digno de aceitação, do respeito e consideração, os "normais" não conseguem the dar esse respeito, e ele mesmo faz eco dessa percepção quando descobre que alguns de seus atributos a garantem ${ }^{2}$.

Num programa de reabilitação psicológica é necessário que se considere os efeitos nocivos da auto-depreciação, do afastamento social e da conduta passiva, voltada para o apiedamento de si mesmo. $O$ ajustamento do paciente somente poderá se fundamentar numa verdadeira aceitação de si mesmo. Deverá ele constituir-se a sua própria referência, sem se comparar com o próximo, somente aceitando um relacionamento com os demais, compativel com o respeito e consideração mútuos, desprezando a falsa condescendência, ou qualquer imposição ou recomendação sobre sua maneira de agir ou sentir, que o faça habitado por um eu que não seja essencialmente ele mesmo. 
GIANNOTTI-HALLAGE, A. Reabilitação psicológica de pacientes com sequelas da encefalite por arborivus. Rev. Saúde pübl., S. Paulo, 15:478-84, 1981.

GIANNOTTI - HALLAGE, A. [Psychological rehabilitation of patients with sequelae due to encephalitis caused by arbovirus]. Rev. Saúde públ., S. Paulo, 15:478-84, 1981.

ABSTRAC $\boldsymbol{T}$ : The possibility of psychological damage in patients with sequelae from encephalitis caused by arbovirus in the southern section of the coastal area of the State of $\mathbf{S}$. Paulo (Brazil) was investigated for the purpose of defining the role of the psychologist in a programme of physical and psychosocial rehabilitation. The presence of the sequelae was regarded depreciatively by the patients and this attitude affected their self-regard as human beings. The result was a series of emotional maladjustments which made it impossible for the patients to live with themselves or maintain a satisfactory relationship with others. The results analyzed from a psychosocial standpoint revealed that the psychological problems observed arose from the way in which the physical deficiency is regarded within the social context. therapy.

UNITERMS: Rehabilitation. Psychology. Encephalitis viruses. PsychoREFERENCIAS BIBLIOGRAFICAS

1. DELAY, J. \& PICHOT, P. El enfermo y sus reacciones a la enfermidad: fatores psicológicos y sociales de las enfermedades. Medicina psicosomática. In: Delay, J. \& PICHOT, P. Manual de psicologia. Barcelona, Toray, 1966. p. 436-55.

2. GOFFMAN, E. Estigma: notas sobre a manipulaça do da identidade deteriorada. Rio de Janeiro, Zahar, 1975.

3. IVERSSON, L.B. Aspectos epidemiolbgicos da encefalite por arbovirus na região do Vale da Ribeira, São Paulo, Brasil, no período de 1975 a 1978. Sảo Paulo, 1979 [Tese de Doutoramento - Faculdade de Saúde Pública da USP].
4. SINGER, $\mathbf{P}$, et al. Prevenir e curar: 0 controle social atraves dos servicos de saude. Rio de Janeiro, Ed. Forense Universitária, 1978.

j. TIRIBA, A. da C. Epidemia de encefalite atribuida a arbovirus, ocorrida no litoral sul do Estado de são Paulo em 1975: contribuiçāo para o estudo clinico. São Paulo, 1975. [Tese de Livre Docência Escola Paulista de Medicina].

6. VAN-ROY, F. El niño impedido. Buenos Ayres, Ed. Kapelusz, 1960.

Recebido para publicação em 11/5/1981

Aprovado para publicasão em 21/07/1981 